\title{
Firm-Level Automation: Evidence from the Netherlands
}

\section{By James Bessen, MaArten Goos, Anna Salomons, and Wiluan van den Berge*}

Advancing technologies are increasingly able to fully or partially automate work and are being adopted across many sectors of the economy. Studying firm-level adjustments is important for understanding the economic effects of such workplace automation. However, empirical work on automation at the firm level is scarce and has so far focused on the manufacturing sector (Doms, Dunne, and Troske 1997) and specifically on industrial robots (Dinlersoz and Wolf 2018; Koch, Manuylov, and Smolka 2019; Humlum 2019; Acemoglu, Lelarge, and Restrepo forthcoming).

While robotics is a prime example of automation technology, it is adopted by a limited number of firms in specific sectors. Direct empirical evidence on the impacts of automation beyond robotics and outside of the manufacturing sector is still lacking.

In this paper, we use a Dutch firm-level survey on automation expenditures linked to administrative records covering the universe of firms in the Netherlands to consider firm-level automation over 2000-2016. While we do not observe the specific automation technology being adopted, ours is an omnibus measure allowing us to study automation across all private nonfinancial sectors of the economy.

We first define automation events at the firm level by exploiting the lumpy nature of automation investments. Next, we show that firms that have automation events experience higher employment growth and revenue growth than firms that do not have these events, consistent with findings for robotics. Using a descriptive

\footnotetext{
* Bessen: Boston University, Technology \& Policy Research Initiative (emal: jbessen@bu.edu); Goos: Utrecht University School of Economics (email: m.goos@uu.nl); Salomons: Utrecht University School of Economics (email: a.m.salomons@uu.nl); van den Berge: CPB Netherlands Bureau for Economic Policy Analysis (email: w.van.den. berge@cpb.nl). James Bessen thanks Google.org for financial support.

${ }^{\dagger}$ Go to https://doi.org/10.1257/pandp.20201004 to visit the article page for additional materials and author disclosure statement $(\mathrm{s})$.
}

event study at the firm level, however, we see that firms do save labor after investing in automation technology, while wages continue to rise. Importantly, these effects arise among both manufacturing and nonmanufacturing firms, indicating that this is not specific to technologies like robotics.

\section{Dutch Firm-Level Data on Automation Expenditures}

We use Dutch data provided by Statistics Netherlands. In particular, we use an annual firm survey covering nonfinancial private sector firms ${ }^{T}$, which includes a direct question on automation costs. We link this survey to administrative company records covering the universe of firms in the Netherlands. Our data cover the years 2000-2016, and we retain 36,490 unique firms with at least 3 years of automation cost data-together, these firms employ around 5 million unique workers annually on average, corresponding to over 60 percent of all employment in the Netherlands. Bessen et al. (2019) outlines further data-processing details.

The main advantage of the dataset we construct is the availability of a direct measure of automation at the firm level. In particular, "automation costs" is an official bookkeeping term defined as costs of third-party automation services. ${ }^{2}$ While the disadvantage of this measure is that we do not know the exact automation technology being used by the firm, it does capture all automation technologies rather than focusing on a single one. These expenditures can be related to automation technologies such as self-service checkouts, warehouse and

\footnotetext{
${ }^{1}$ Firms are legally obliged to respond to the survey when sampled. The sampling design is that firms with more than 50 employees are surveyed every year along with a subset of smaller nonfinancial private firms; this implies that our data underrepresent smaller firms.

${ }^{2}$ This also includes nonactivated purchases of custom software and costs of new software releases but excludes prepackaged software licensing costs.
} 
storage systems, data-driven decision-making, and automated customer service, as well as the type of robotics integrator services highlighted in Acemoglu and Restrepo (forthcoming).

Figure 1 shows the firm-level distribution of annual automation costs per worker separately for manufacturing and nonmanufacturing firms. ${ }^{3}$ This highlights that firms have become more automation intensive over this period: mean firm-level automation expenditures have risen from 744 to 1,103 real euros per worker on average. Further, these increases have been more pronounced at the top of the distribution, as many firms are not observed to automate at all: indeed, close to one-third of firm-year observations have zero automation expenditures. Lastly, automation extends beyond robotics, as similar patterns emerge across manufacturing and nonmanufacturing firms.

\section{Identifying Automation Events}

We observe that automation expenditures are lumpy: a significant share of investment occurs in episodes of relatively large quantities. This allows us to construct automation events at the firm level as years when automation expenditures spike compared to what the firm normally spends on these services.

We define these events as follows. Firm $j$ has an automation cost spike in year $\tau$ if its real automation costs $A C_{j \tau}$ relative to real total operating costs (excluding automation costs) averaged across all years $t, \overline{T C}_{j}$, are at least thrice the average firm-level cost share excluding year $\tau$ :

(1) spike $_{j \tau}=1\left\{\frac{A C_{j, t=\tau}}{\overline{T C}_{j}} \geq 3 \times \frac{\overline{A C}_{j, t \neq \tau}}{\overline{T C}_{j}}\right\}$,

where $\mathbf{1}\{\cdot\}$ denotes the indicator function. As such, a firm that has automation costs around 1 percent of all other operating costs for year $t \neq \tau$ will be classified as having an automation spike in $t=\tau$ if its automation costs in $\tau$ exceed 3 percent of average operating costs over years $t$.

We interpret this as a flag for firm-level automation-related events, even though we

\footnotetext{
${ }^{3}$ The nonmanufacturing sectors included in our data are construction; wholesale and retail trade; transportation and storage; accommodation and food serving; information and communication; professional, scientific, and technical activities; and administrative and support activities.
}

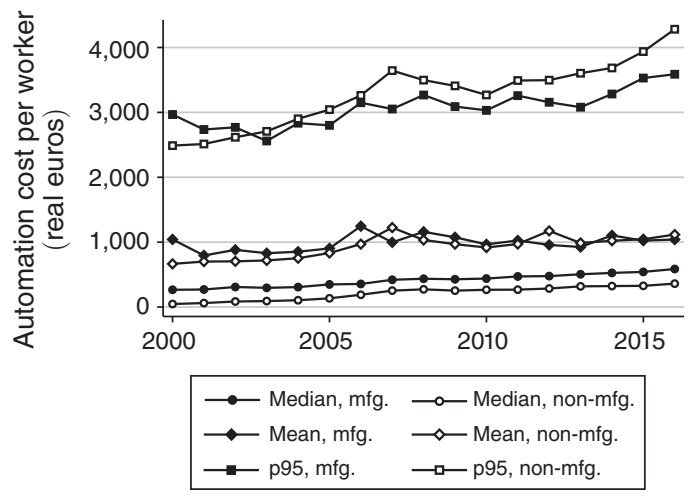

Figure 1. Firm-Level Automation Cost Per Worker OVER TIME

are agnostic about their exact size since we do not measure all automation-related expenditures (such as hardware costs). Among the 36,490 firms in our sample, 10,476 (or around 30 percent) have such automation events, and this incidence is similar in manufacturing and nonmanufacturing sectors. Bessen et al. (2019) shows these automation spikes in event time, illustrating the lumpiness of investment.

\section{How Do Automating Firms Differ?}

We now ask how firms with automation events differ from those without automation events: as outcomes, we consider employment, daily wage, and revenue growth. ${ }^{4}$ In particular, we estimate variants of the following model:

$$
\text { (2) } \Delta \ln Y_{j t}=\beta \times A_{j}+D_{t}+\gamma \times X_{j}+\varepsilon_{j t},
$$

where the dependent variables are annual log changes in outcomes for firm $j$ and year $t$. The variable $A_{j}$ is a dummy for the firm having an automation event over the 2000-2016 period, $D_{t}$ are year fixed effects, and $X_{j}$ are firm-level controls (two-digit sector fixed effects and initial-year values for $\log$ employment, $\log$ mean daily wages, and log revenues). All models are weighted by the inverse of the number

\footnotetext{
${ }^{4}$ The sources for employment and wage data are administrative company records, while revenue data are from a firm-level survey. We use daily wages because our data do not contain information on hours worked.
} 
Table 1-Firm-Level Outcomes for Automating Versus Nonautomating Firms

\begin{tabular}{|c|c|c|c|c|c|c|}
\hline & \multicolumn{2}{|c|}{$\Delta$ log employment } & \multicolumn{2}{|c|}{$\Delta \log$ mean daily wage } & \multicolumn{2}{|c|}{$\Delta \log$ revenue } \\
\hline & (1) & (2) & (3) & (4) & $(5)$ & (6) \\
\hline Automate & $\begin{array}{c}0.018 \\
(0.008)\end{array}$ & $\begin{array}{c}0.020 \\
(0.006)\end{array}$ & $\begin{array}{c}0.002 \\
(0.002)\end{array}$ & $\begin{array}{c}0.001 \\
(0.002)\end{array}$ & $\begin{array}{c}0.013 \\
(0.006)\end{array}$ & $\begin{array}{c}0.010 \\
(0.006)\end{array}$ \\
\hline Automate $\times$ manufacturing & $\begin{array}{c}0.000 \\
(0.012)\end{array}$ & $\begin{array}{c}-0.005 \\
(0.010)\end{array}$ & $\begin{array}{r}-0.003 \\
(0.004)\end{array}$ & $\begin{array}{c}0.001 \\
(0.003)\end{array}$ & $\begin{array}{r}-0.000 \\
(0.012)\end{array}$ & $\begin{array}{c}-0.001 \\
(0.009)\end{array}$ \\
\hline Additional controls & No & Yes & No & Yes & No & Yes \\
\hline
\end{tabular}

Notes: $N=165,625$ firm-year observations, where 10,476 out of 36,490 unique firms automate. All models include year fixed effects and a dummy for the manufacturing sector. All models are weighted by the inverse of the number of firm-level observations multiplied by baseline firm-level employment size. Additional firm-level controls are two-digit sector fixed effects and baseline values for log employment, log mean daily wage, and log revenues. Standard errors are clustered at the firm level.

of firm-level observations ${ }^{5}$ multiplied by initial-year firm-level employment. Standard errors are clustered at the firm level. The coefficient of interest, $\beta$, tells us whether automating firms experience different employment, mean daily wage, and revenue trajectories. We additionally interact this with a manufacturing dummy to test whether this association is significantly different for automating firms in the manufacturing sector.

Our findings, reported in Table 1, are that automating firms have 1.8 to 2 percent higher employment and 1 to 1.3 percent higher revenue growth annually, though not higher daily wage growth, compared to nonautomating firms. Further, the association between automation and firm outcomes is not significantly different for manufacturing firms compared to nonmanufacturing ones, as seen from the economically small and statistically insignificant interaction term coefficients.

These findings are consistent with an emerging literature studying firm-level adoption of robotics, where firms adopting robots are shown to have faster employment and output growth compared to nonadopters (Dixon, Hong, and $\mathrm{Wu} 2019$; Koch, Manuylov, and Smolka 2019; Acemoglu, Lelarge, and Restrepo forthcoming). However, our results hold for automation much more broadly.

\footnotetext{
${ }^{5}$ While not important for our results, this weighting is done because we have an unbalanced panel.
}

\section{An Automation Event Study}

The expansion of automating firms relative to nonautomating ones does not rule out that automation at the firm level can be labor saving when it occurs; such labor-saving effects would matter for individual workers employed in these automating firms. We therefore also consider the evolution of firm outcomes around these automation events, looking at the subsample of automating firms. Our event study equation is

$$
\text { (3) } \ln Y_{j t}=\sum_{t \neq-1 ; t=-3}^{4} \beta_{t} \times I_{t}+\gamma \times X_{j t}+\varepsilon_{j t},
$$

where as before $j$ indexes firms, and $t$ is now defined as event time, that is, calendar year minus the firm-specific event year, $t=$ year $-\tau$. Here, $I_{t}$ are leads and lags for firms having an automation event, with $t=-1$ as the reference category. Finally, $X_{j t}$ are a set of controls, specifically calendar year and firm fixed effects. Since revenue data are sparse and we use a balanced-panel event study, we use employment and daily wages (which both derive from administrative records) as our outcome variables. Lastly, we estimate these models separately for manufacturing and nonmanufacturing firms.

Results from this descriptive event study are shown in Figure 2. Here, we see that after the automation event, firm-level employment contracts. Even as automating firms expand employment compared to nonautomating ones on average over the entire period, employment growth following automation appears slower. Although these effects are quantitatively larger 

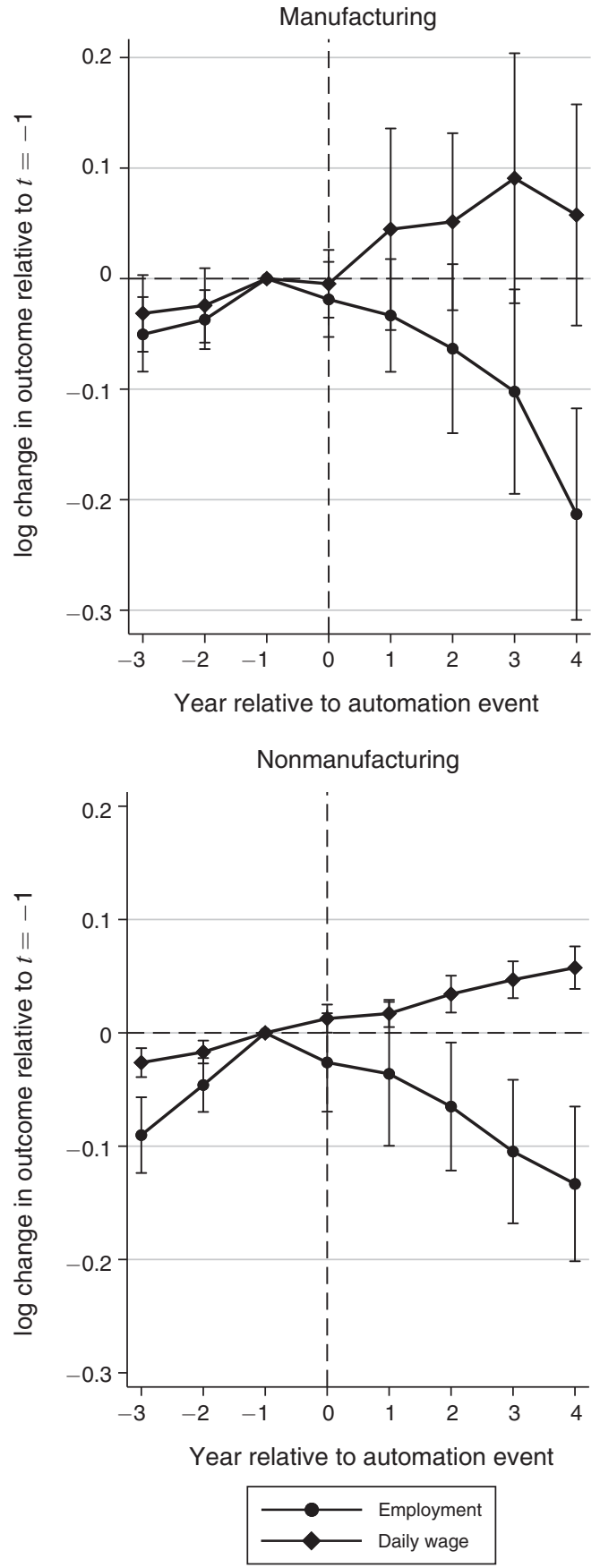

Figure 2. Firm-Level Employment and Mean Real DAILY WAGE

Notes: Balanced panel. $N=2,616$ for manufacturing, 16,952 for nonmanufacturing. Both models are weighted by firm-level employment size in $t=-1$. Standard errors are clustered at the firm level. Whiskers reflect 95 percent confidence intervals. (albeit more imprecisely estimated) in manufacturing, they are observed in nonmanufacturing firms as well, suggesting that this is not specific to technologies like robotics. In contrast to employment growth, daily wages continue to grow during these events, as distinct from other firm-level labor-saving events such as mass layoffs.

\section{Conclusion}

Studying firm-level adjustments is important for understanding the economic effects of workplace automation. So far, emerging empirical evidence at the firm level is focused on robotics and the manufacturing sector. In this paper, we have documented that the adoption of automation technologies extends beyond firms in the manufacturing sector. We identify firm-level automation events and show that automating firms experience faster employment and revenue growth than do nonautomating firms. However, around automation events themselves, employment growth slows markedly. Notably, we find that these effects are similar for both manufacturing and nonmanufacturing firms, suggesting that the increasing adoption of automation technology across a wide range of sectors of the economy has important consequences for firms and their workers.

\section{REFERENCES}

Acemoglu, Daron, Claire Lelarge, and Pascual Restrepo. Forthcoming. "Competing with Robots: Firm-Level Evidence from France." AEA Papers and Proceedings.

Acemoglu, Daron, and Pascual Restrepo. Forthcoming. "Robots and Jobs: Evidence from US Labor Markets." Journal of Political Economy.

Bessen, James, Maarten Goos, Anna Salomons, and Wiljan van den Berge. 2019. "What Happens to Workers at Firms That Automate?" https://papers.ssrn.com/sol3/papers.cfm?abstract_id=3328877.

Dinlersoz, Emin, and Zoltan Wolf. 2018. "Automation, Labor Share, and Productivity: PlantLevel Evidence from US Manufacturing." US Census Bureau Center for Economic Studies Working Papers 18-39.

Dixon, Jay, Bryan Hong, and Lynn Wu. 2019. "The Employment Consequences of Robots: Firm-Level Evidence." http://content. 
tcmediasaffaires.com/LAF/lacom2019/ robots.pdf.

Doms, Mark, Timothy Dunne, and Kenneth R. Troske. 1997. "Workers, Wages, and Technology." Quarterly Journal of Economics 112 (1): 253-90.
Humlum, Anders. 2019. "Robot Adoption and Labor Market Dynamics." https:// economics.yale.edu/sites/default/files/ humlumjmp_111419.pdf.

Koch, Michael, Ilya Manuylov, and Marcel Smolka. 2019. "Robots and Firms." CESifo Working Paper 7608. 